Article

\title{
An Investigation of Multimodal Transport for Last Mile Delivery in Rural Areas
}

\author{
Xiaofei Kou ${ }^{1, *}$, Yanqi Zhang ${ }^{1, *}$, Die Long ${ }^{2}$, Xuanyu Liu ${ }^{1}$ and Liangliang Qie ${ }^{3}$ \\ 1 School of Management Engineering, Zhengzhou University of Aeronautics, Zhengzhou 450046, China; \\ 1xy18736709872@163.com \\ 2 Office of Industrial Administration, Zhengzhou University of Aeronautics, Zhengzhou 450046, China; \\ 1d712yes@163.com \\ 3 School of Chemistry and Material Science, Hubei Engineering University, Xiaogan 432000, China; \\ qieliang1010@163.com \\ * Correspondence: kxfei1987@zua.edu.cn (X.K.); yeonki@zua.edu.cn (Y.Z.)
}

Citation: Kou, X.; Zhang, Y.; Long, D.; Liu, X.; Qie, L. An Investigation of Multimodal Transport for Last Mile Delivery in Rural Areas. Sustainability 2022, 14, 1291. https:// doi.org/10.3390/su14031291

Academic Editor: Aoife Ahern

Received: 31 December 2021

Accepted: 18 January 2022

Published: 24 January 2022

Publisher's Note: MDPI stays neutral with regard to jurisdictional claims in published maps and institutional affiliations.

Copyright: (C) 2022 by the authors. Licensee MDPI, Basel, Switzerland. This article is an open access article distributed under the terms and conditions of the Creative Commons Attribution (CC BY) license (https:// creativecommons.org/licenses/by/ $4.0 /)$.

\begin{abstract}
High distribution costs constitute one of the major obstacles to the sustainable development of rural logistics. In order to effectively reduce the distribution costs of last mile delivery in rural areas, based on three typical transport modes (local logistics providers, public transport, and crowdsourcing logistics), this study first proposes a multimodal transport design for last mile delivery in rural areas. Then, a cost-benefit model for multimodal transport is proposed which uses genetic algorithms (GA) to solve the logistical problems faced. Finally, Shapley value is used to fairly allocate profits and represent the marginal contribution of each mode in multimodal transport. The numerical results show that multimodal transport can effectively reduce the distribution costs of last mile delivery in rural areas. When the order demand of each node tends to be stable, the marginal contribution of crowdsourcing logistics is often greater than that of the other two distribution modes. The marginal contribution of public transport is highest only when the number of orders per node is very small.
\end{abstract}

Keywords: rural logistics delivery; multimodal transport; cost-benefit analysis; profit allocation

\section{Introduction}

In recent years, the continuous development of e-commerce business has driven the rapid development of rural logistics. Since the COVID-19 pandemic, the physical retail industry has been hit hard and online shopping has gradually become one of the most important consumption patterns. According to a report [1], in the first three quarters of 2021, China's online retail sales reached 1.441 trillion dollars, up $18.5 \%$ year on year. Meanwhile, rural e-commerce business continued to grow; in the first three quarters of 2021, rural online retail sales registered 224.1 billion dollars, up by $16.3 \%$. In order to meet the rapidly growing logistical demands of 200 million rural on-line users, it is necessary to build a more efficient and high-quality rural terminal logistics distribution service network. However, rural logistics is still backward, and the development of rural logistics faces many problems, such as low information levels, poor distribution service quality, small distribution network ranges, long distribution times, and so on. These problems lead to the high distribution costs of last mile delivery in rural areas and hinder the further development of rural logistics.

Last mile delivery has always been one of the most complicated and costly links in the supply chain. Last mile delivery corresponds to the last leg in the distribution process, whereby a consignment is delivered from the last distribution point, either a warehouse or a distribution center, to the recipient, either at the recipient's home or at a collection point [2]. 
Last mile delivery is connected to customers, and service quality directly affects customers' experiences. With the continuous growth of urban populations, last mile delivery is facing various problems and challenges, such as traffic congestion, environmental pollution, noise pollution, high distribution costs, etc. [3]. How to reduce distribution costs has become the most critical problem.

Route optimization is an important method to reduce costs and improve the distribution efficiency of logistics. Route optimization in last mile delivery is the typical vehicle route problem (VRP). The VRP was first proposed by Dantzig and Ramser in 1959 [4]. In the following 60 years, VRP optimization has evolved different research directions based on the specific characteristics of the problem and different solution methods. Considering the specific characteristics of the problem, scholars divide the VRP optimization problem into VRPs with a time window [5-8], multi-depot VRP optimization [9-12], green VRPs [13,14], and rich VRPs [15-17]. On the other hand, according to the characteristics of the problem, using different methods to solve the VRP is also one of the significant challenges for research. For example, intelligent optimization algorithms, such as genetic algorithms [18,19], simulated annealing algorithms [20,21], tabu search algorithms [22,23], and ant colony algorithms [24-26], are used to solve the vehicle routing optimization problem.

The above research is intended to reduce distribution costs and improve distribution efficiency by route optimization based on existing distribution modes. Using different distribution modes to improve distribution efficiency and reduce the cost of last mile delivery is also one of the important tasks for current research. In recent years, with the rapid development of the sharing economy, mobile crowdsourcing has been a hot research topic in logistics distribution. Rouges [27] and Carbone [28] provided comprehensive reviews of crowdsourcing for last mile delivery. Wang proposed an effective large-scale mobile crowd-tasking model in which a large pool of citizen workers is used to perform last-mile delivery. The parcels are assigned to shared reception boxes or pop-stations, from which the crowdsourced workforce collect them and then deliver them to the customers [29]. Huang studied the planning of last mile delivery with partial crowdsourcing integration. The results showed that well-planned crowdsourcing integration can take advantage of the flexibility and cost-saving of crowdsourcing for last mile delivery [30]. Kafle proposed a crowdsource-enabled system for urban parcel replay and delivery. By adopting this new system, the number of truck vehicle miles traveled and total costs can be reduced compared to pure truck delivery [31]. Akeb designed an urban crowdsourced delivery system to deal with the unattended parcel problem. In this framework, the nearest available crowdsource can accept a parcel if its recipient is away from home [32]. Chen proposed the idea of using a taxi as a crowd-worker to carry out last mile delivery [33]. Crowdsourced logistics is an effective method to solve the last mile delivery problem in rural areas. Many scholars have undertaken a lot of outstanding research and made great progress. However, most of the current research focuses on using crowdsourcing modes to replace the existing distribution mode, while there is less research on multimodal transport for last mile delivery. In addition, most of the research focuses on urban logistics distribution.

Last mile delivery in rural logistics is similar to urban logistics, facing problems such as high distribution costs and serious environmental pollution. However, due to the vast geographical areas and the sparse populations in rural areas, last mile delivery in rural logistics has its own characteristics. Compared with urban logistics distribution, the distance between distribution nodes is longer, and order quantities at each node are less in rural areas, which leads to higher distribution costs. Thus, most rural areas cannot enjoy the same distribution services as urban areas. Compared with online shopping, villagers prefer WYSIWYG ("What you see is what you get") shopping in physical stores. Therefore, the low quality and low efficiency of logistics distribution in rural areas are considered two of the important factors hindering the sustainable development of the rural economy. How to provide normal daily distribution services is an urgent problem to be solved in rural areas. 
Encouraging different logistics enterprises to share resources and collaborative distribution between different transportation modes, as well as accelerating the construction of basic logistics facilities in rural areas, have all become important measures to promote the sustainable development of rural logistics and realize the strategy of rural revitalization. As one of the major drivers of sustainable development, multimodal transport has developed rapidly in the past decades [34-37]. Extensive research has been carried out on various aspects of multimodal transport, such as multimodal travel [38], multimodal routing problems [39], and multimodal pricing [40]. Solving the last mile delivery problem in rural areas with multimodal transport has gradually become a hot research topic. Chen et al. [41] found that China Post has a very strong advantage in rural logistics, and multimodal transport could improve the service quality of last mile delivery. Gong proposed integrated urban-rural logistical systems, including material flow, financing flow, information flow, and commerce flow, which has become an effective way to break through the division between urban and rural logistics and realize their coordinated development [42]. Yang [43] proposed a cooperative rich vehicle routing problem among local logistics providers, logistics providers concerned with integrated delivery and installation, and commercial express enterprises. The results showed that a long-term grand coalition will be beneficial to all the participators. In addition, multimodal transport involving drones and vehicles is also considered to be one of the effective methods to solve the last mile delivery problem in rural areas [44-46].

Although extensive knowledge has been accumulated through previous research, the focus has mostly been on last mile delivery in urban areas, the strategies for which cannot be directly adopted in rural areas. There are few studies on the integration of public passenger resources, crowdsourcing logistics, and the adoption of multimodal transport for last mile delivery in rural areas by local logistics providers. Multimodal transport for last mile delivery in rural areas has not been widely accepted by the general public due to poor coordination among transport modes and difficulties in terms of cost-benefit analyses. Meanwhile, the difficulty of allocating orders between different transportation modes is another challenge for multimodal transport. At present, many logistics and distribution platforms or enterprises can provide various forms of logistics services, but the service content of each platform and enterprise is relatively single and homogeneous and cannot well integrate idle transport resources in rural areas, nor effectively improve the quality of last mile delivery.

Logistics service quality includes many factors. The issue to be solved in this research is how to provide the same daily distribution service in rural areas as in urban areas. Among many logistics service quality problems, distribution cost is the key issue. Therefore, in the subsequent analysis, this research only considers distribution cost and its related factors.

Taking the above problems into consideration, this research focuses on the design of a multimodal transport service to solve the last mile delivery problem in rural areas. Three questions should be answered for designing the multimodal transport service: (1) How to assign orders to different transport modes? (2) How to develop cost-benefit analysis models? and (3) How to allocate profits among different transportation modes? Focusing on these questions, this research first proposes a design for multimodal transport for last mile delivery in rural areas. Then, a cost-benefit model for multimodal transport is constructed which uses genetic algorithms (GAs) to solve the model problem. Finally, Shapley values are used to fairly allocate profits and represent the marginal contribution of each mode in multimodal transport.

The rest of this paper is organized as follows: Section 2 analyses the scenario of last mile delivery in rural areas. Meanwhile, a distribution cost model is developed to analyze the cost-benefit components, and a profit allocation method is proposed. An experimental case study is conducted to investigate the multimodal route recommendation and profit allocation in Section 3. Finally, the discussion and conclusions are presented in Sections 4 and 5, respectively. 


\section{Materials and Methods}

\subsection{Problem Analysis}

As shown in Figure 1, logistics transportation in rural areas is divided into three parts: logistics transportation from urban areas to township areas (trunk transportation), the logistics distribution service in township areas (branch transportation), and the logistics distribution service from township areas to rural areas (branch transportation). For logistics transportation from urban areas to township areas, the express enterprises transport orders to the distribution center of local logistics services providers (LLPs) using their own vehicles. Meanwhile, the express enterprises pick up the orders from the LLPs and transport them back to a distribution center in the city. The logistics distribution service in a town is provided by an LLP, which can realize the distribution on the same day or the next day. Due to the small quantity of orders and high distribution costs, LLPs usually adopt two ways to solve the last mile delivery problem in rural areas: (1) the LLPs accumulate the orders to a certain amount and then distribute them. In this way, the LLPs will distribute the orders only once every few days or even a week; (2) in addition to providing a distribution service for orders with installation demands (installation needs can provide added value), LLPs are only responsible for the logistics distribution in township areas; other orders are picked up by the villagers themselves and the distribution service is not provided (as shown by the dotted line in Figure 1). The current distribution mode means that villagers cannot enjoy the same high-quality logistics distribution services as urban residents when shopping online, which seriously hinders the further development of e-commerce, and the backwardness of logistical systems hinders the upstream channeling of agricultural products and affects the further development of the rural economy.

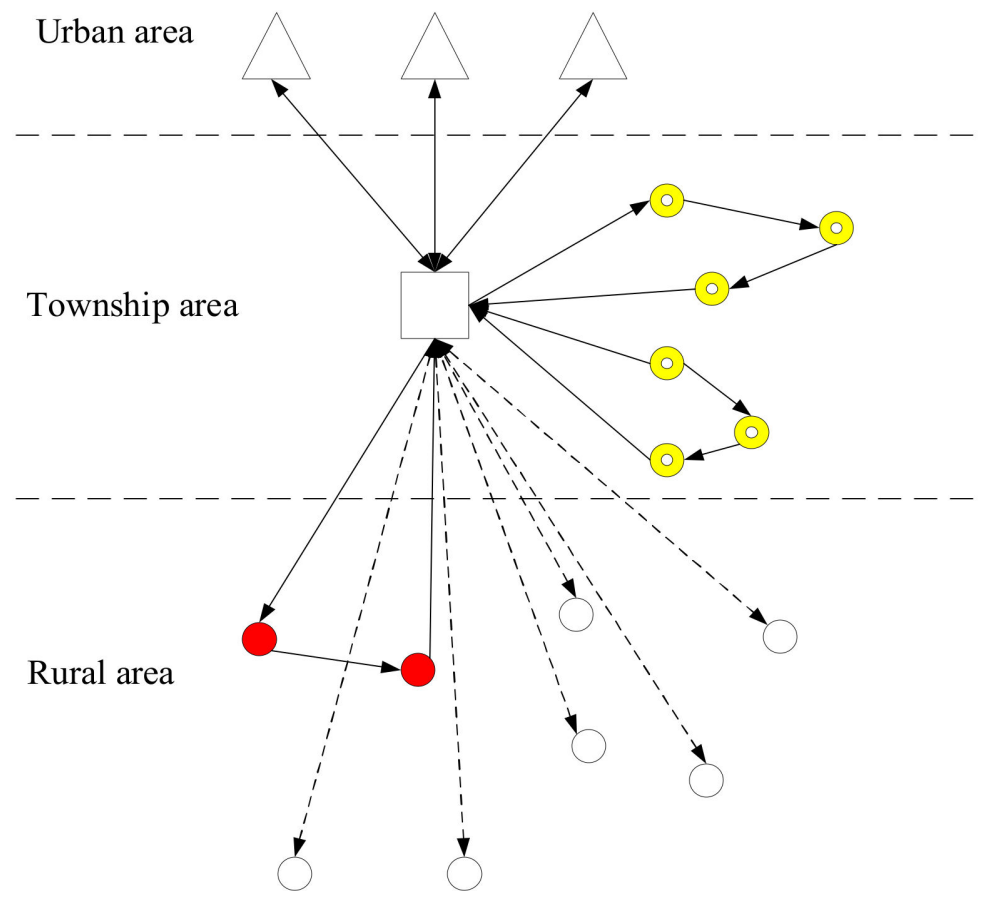

Local logistics provider

Express enterprise

Figure 1. Problem analysis. 
Most rural areas are sparsely populated, so it is difficult for enterprises to provide highquality logistics distribution services with sure expectations of profits. Meanwhile, in most rural areas of China, in order to ensure the normal travel needs of villagers, the government will arrange at least one bus in each village every day, while passenger transport companies (PTs) often operate at a loss, the expenses to be eventually subsidized by the government. For most of the year, the seasonal characteristics of labor and the lack of additional income in rural areas leads to an idle labor force. Therefore, integrating passenger transport, idle labor, and the transport resources of LLPs for multimodal transport is one of the effective ways to solve the last mile delivery problem in rural areas without increasing or slightly increasing infrastructure. In addition, it can also provide additional income for PT companies and idle rural labor and promote the sustainable development of the rural economy.

This paper only studies last mile delivery in rural areas. The logistics transportation from urban areas to township areas and the logistics distribution in township areas are similar to urban logistics. A large number of researchers have studied this problem and no further analysis is made here.

\subsection{Cost-Benefit Analysis}

Cost-benefit analysis is the most important aspect of multimodal transport research concerning last mile delivery and it is the basis of route optimization and profit distribution. In this section, firstly, the last mile delivery problem of rural logistics is analyzed, and the distribution cost model is proposed. Secondly, the distribution modes of multimodal transport are analyzed and the distribution cost model is constructed. Finally, the saved distribution cost is taken as the profits and Shapley values are used to allocate the profits among the different distribution modes.

Referring to the literature [43], symbols are used as follows:

- Indices and sets:

$O=\{1,2,3\}$ : The depots of three transport modes: local logistics provider (LLP), public transportation (PT) and crowdsourcing logistics (CL). Let $l(o)$ be the virtual ending node corresponding to depot $o \in O$, and let $\mathrm{L}$ denote all the virtual ending nodes.

$C$ : The customer nodes with $C=D^{L} \cup D^{P} \cup D^{E} \cup D^{V}$, in which the subsets respectively represent the delivery $(D)$ orders of the LLP (superscript $L), \mathrm{PT}(P)$, and CL $(E) . D^{V}$ represents the orders picked up by the villagers themselves. $D^{L}$ is also the customer node with installation services.

$K_{o}$ : Vehicles available for rural logistics corresponding to depot $o$.

- Parameters:

$c_{o k i j}$ : Transportation cost from node $i$ to $j$ for vehicle $k$ that departs from depot $o$, where $o \in O, k \in K_{0}$, and $i, j \in C \cup O \cup L$.

$e_{0}$ : Labor cost of each utilized vehicle that departs from depot $o \in O$.

$q_{i}$ : Delivery demand at point $i \in C$.

$\alpha_{o i}$ : Indicator that if the orders at node $i$ belong to the transport mode that owns depot $o, \alpha_{o i}=1$; otherwise, $\alpha_{o i}=0$.

$Q_{o k}$ : Carrying capacity of vehicle $k$ departing from depot $o$.

$c_{i 1}^{v}$ : The pick-up cost from node $i$ to depots of LLP for villagers, where $i \in D^{V}$.

$e_{i 1}^{v}$ : Labor cost of villagers depart from node $i$ to depots of LLP for villagers, where $i \in C \backslash D^{L}$.

$P_{C}$ : Penalty cost when installation service is not provided.

$b_{i}$ : Penalty cost when the installation service of $i$ th node is not satisfied.

- Decision variables:

$x_{o k i j}$ : Indicator that if vehicle $k$ from depot $o$ visits node $j$ departure from node $i$, $x_{o k i j}=1$; otherwise, $x_{o k i j}=0$. 
2.2.1. The Cost Analysis of Last Mile Delivery in Rural Areas

At present, the distribution mode of last mile delivery in rural areas is shown in Figure 2.

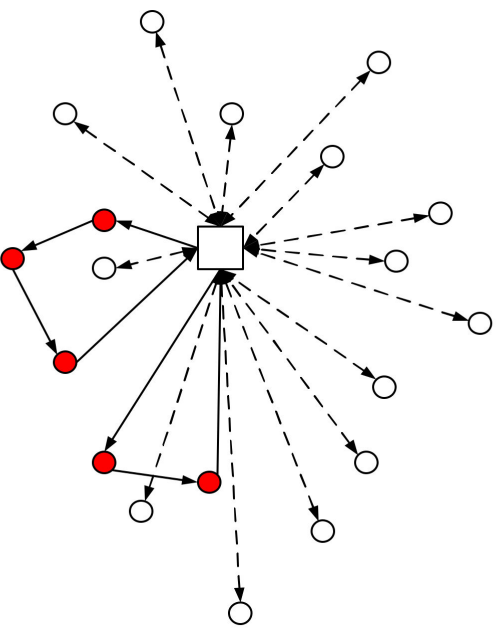

Local logistics provider $\bigcirc$ Delivery order

Delivery and installation orders

Delivery service

---- Villagers pick up orders themselves

Figure 2. Logistics distribution mode in rural areas.

The most common solution for last mile delivery in rural areas is that orders with installation demands (with additional added value) need to be delivered by technical personnel working for the LLP (as shown by the red dot and solid line in Figure 2). Meanwhile, other orders in the corresponding villages will be delivered along with them and the constraints of carrying capacity need to be met in the distribution process, while orders in other villages are picked up by the villagers themselves at the distribution center in the town. Therefore, the current distribution cost is mainly composed of the distribution cost of the LLP and the villagers' pick-up costs.

Without loss of generality, we make the following assumptions:

- Each village has a receiving point for orders, and the vehicle only needs to transport the orders to the receiving point.

- Vehicles from the LLP can only deliver orders from the same villages, and other orders cannot be delivered.

- The distribution vehicle has a constraint of carrying capacity.

- When the villagers pick up the orders by themselves, the orders of the same village are picked up by one villager. Each village only needs to pick up the orders once a day.

- $\quad$ Orders at each distribution node cannot be split.

Referring to Figure 2, a total cost model for last mile delivery in rural areas can be formulated.

$$
T C_{C}=\sum_{i \in D^{V}} C_{i 1}^{V}+\sum_{k \in K_{1}} \sum_{i \in D^{L}} \sum_{j \in D^{L}} c_{1 k i j} x_{1 i j k}+e_{1} \sum_{k \in K_{1}} \sum_{j \in D^{L}} x_{1 k 1 j}
$$

s.t.

$$
\begin{aligned}
& \sum_{j \in D^{l} \cup\{l(1)\}} x_{1 k 1 j}=\sum_{i \in D^{l} \cup\{1\}} x_{1 k i l(1)} \leq 1, \quad \forall k \in K_{1} \\
& \sum_{i \in D^{l} \cup\{1\}} x_{1 k i j}=\sum_{i \in D^{l} \cup\{l(1)\}} x_{1 k j i}, \quad \forall k \in K_{1}, \quad \forall j \in D^{l}
\end{aligned}
$$




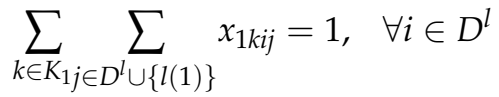

$$
\begin{aligned}
& \sum_{j \in D^{l}} q_{j} x_{1 k i j} \leq q_{1 k}, \quad \forall k \in K_{1}, \quad \forall i \in D^{l} \cup\{1\} \\
& x_{1 k i j} \in\{0,1\}, \quad \forall k \in K_{1}, \quad \forall i \in D^{l} \cup\{1\}, \quad \forall j \in D^{l} \cup l
\end{aligned}
$$

where the objective function (1) represents the total distribution cost of last mile delivery in current rural areas, which is composed of three parts: the cost for villagers to pick up orders by themselves, the distribution cost of LLP for the orders with installation demands, and the labor cost. Constraint (2) forces each vehicle to depart from and return to the depot of the LLP. Constraint (3) ensures the conservation of the arrival and departure at each node. Constraint (4) represents the installation service that can only be provided by LLPs. Constraint (5) ensures that each vehicle capacity cannot be exceeded. Constraint (6) comprises the definitions of the visiting variables.

\subsubsection{The Cost Analysis of Multimodal Transport in Rural Logistics}

The distribution mode of multimodal transport for last mile delivery in rural areas is shown in Figure 3.

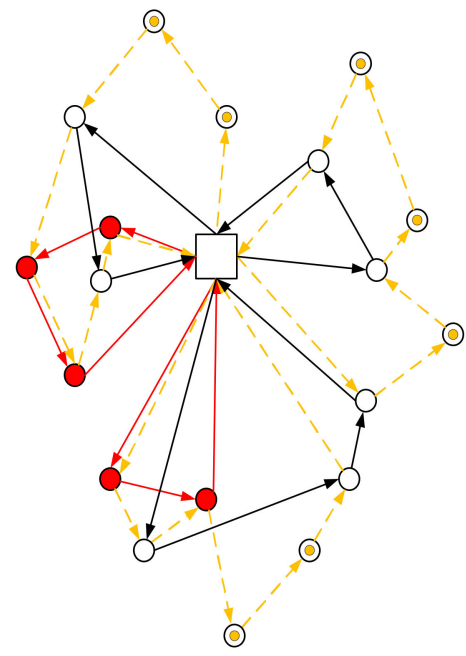

Delivery and installation orders

길 Delivery orders served by PT

Delivery orders served by $\mathbf{C L}$

$---\quad$ PT transportation route

$\longrightarrow \quad$ LLP transportation route

$\longrightarrow \quad$ CL transportation route

Local logistics provider

Figure 3. Multimodal transport for last mile delivery in rural areas.

In order to solve the last mile delivery problem in rural areas, LLP, PT, and crowdsourcing logistics (CL) provide transportation resources for distribution services. Similar to the current distribution mode, LLPs provide logistics distribution services when the orders need value-added services, such as installation. The transport resources provided by PT have the characteristics of timing and fixed route, and the PT resources pass through all villages every day. Therefore, the transportation resources provided by the PT can traverse each node, but due to the limited cargo capacity of the PT itself, it can only meet the distribution needs of some nodes. The remaining orders need to be delivered by CL. Thus, the transportation cost of multimodal transport for last mile delivery is mainly composed of three parts: the transportation costs of the LLP, PT, and CL. In this section, we still use the assumptions introduced in Section 2.2.

- Order allocation principle 
Before distribution cost modeling, we need to allocate orders among the three transport modes. The specific allocation principles are as follows:

(1) Orders requiring installation and other value-added services are allocated to the LLP.

(2) We allocate the furthest orders to the PT and use the PT cargo capacity as much as possible.

(3) The remaining orders are delivered by the CL.

- Distribution cost model

Referring to Figure 3, a total cost model of multimodal transport for last mile delivery in rural areas can be formulated.

$$
T C_{M}=\sum_{o \in O} \sum_{k \in K_{o}} \sum_{i \in C \cup\{o\}} \sum_{j \in C \cup\{l(o)\}} c_{o k i j} x_{o k i j}+\sum_{o \in O} e_{o} \sum_{k \in K_{O}} \sum_{j \in C} x_{o k o j}+P_{C}
$$

s.t.

$$
\begin{gathered}
\sum_{j \in C \cup\{l(o)\}} x_{o k o j}=\sum_{i \in C \cup\{o\}} x_{o k i l(o)} \leq 1, \quad \forall k \in K_{o}, \quad \forall o \epsilon O \\
\sum_{i \in C \cup\{o\}} x_{o k i j}=\sum_{i \in C \cup\{l(o)\}} x_{o k j i}, \quad \forall k \in K_{o}, \quad \forall j \in C, \quad \forall o \epsilon O \\
\sum_{o \in O} \sum_{k \in K_{o}} \sum_{j \in C \cup\{l(o)\}} x_{o k i j}=1, \quad \forall i \in C \\
\sum_{j \in C} q_{j} x_{o k i j} \leq Q_{o k}, \quad \forall k \in K_{o}, \quad \forall i \in C \cup\{o\}, \quad \forall o \epsilon O \\
x_{o k i j} \in\{0,1\}, \quad \forall o \epsilon O, \quad \forall k \epsilon K_{o}, \quad \forall i \in C \cup O, \quad \forall j \in C \cup L \\
D^{V}=\varnothing \quad \begin{array}{c}
0 \\
\sum_{C} b_{i}
\end{array} \quad D^{L}=\varnothing
\end{gathered}
$$

where the objective function (7) represents the total distribution cost of multimodal transport for last mile delivery in rural areas. The objective function is composed of three parts: the total transportation cost of multimodal transport, the labor cost, and the penalty cost when an installation service is not provided by the LLP. Constraint (8) forces each vehicle to depart from and return to the same depot. Constraint (9) ensures the conservation of arrival and departure at each node. Constraint (10) denotes that the demands of each transport mode must be satisfied. Constraint (11) ensures that each vehicle capacity cannot be exceeded. Constraint (12) comprises the definitions of the visiting variables. Constraint (13) represents all orders that are delivered to demand points through one of the transport modes. Constraint (14) represents the penalty cost when an installation service is not provided.

\subsubsection{Analysis of the Profit Distribution Strategy}

For the last mile delivery problem in rural areas, the total profit of the logistics distribution system refers to the distribution cost saved by using multimodal transport compared with the existing distribution mode. Thus, the total profit of multimodal transport for last mile delivery is as follows:

$$
P_{T}=\min \left(T_{C}\right)-\min \left(T_{M}\right)
$$

where $T_{C}$ represents the total cost of the current distribution mode in rural areas and $T_{M}$ represents the total cost of multimodal transport for last mile delivery in rural areas. 
In the research, Shapley value is used to allocate the profit. Shapley value was proposed by Lloyd Shapley [47]. It is a profit allocation method based on a cooperative game. The profit allocation based on Shapley value reflects the contribution of each alliance member to the overall goal of the alliance and avoids equalitarianism in allocation. This method is more reasonable than any profit allocation method that only considers the value of the resource input, the efficiency of resource allocation, and the combination of the two. It also reflects the process of a game among alliance members. Shapley value can effectively solve the profit allocation problem in the process of multi-member cooperation, and its greatest contribution is to allocate profits according to the marginal contribution rate of members to the alliance-that is, the benefit of member $i$ is equal to the average of the marginal benefits created by the member in the alliance. Generally, the Shapley value can be obtained as:

$$
\varphi_{i}(v)=\sum_{s \in S_{i}} \frac{(|s|-1) !(n-|s|) !}{n !} \times[v(s)-v(s \backslash\{i\})]
$$

where $\varphi_{i}(v)$ represents the profit that results from member $i$ entering into sub-alliance $s$, $n$ is all the members of cooperative game system, $v(s)$ represents the benefits of alliance $s$, and $(|s|-1) !(n-|s|) ! / n !$ can be regarded as the probability of member $i$ entering into sub-alliance $s$.

When Shapley value is used for profit allocation, the profit of each alliance needs to be calculated and three members have six alliance combinations. As shown in Table 1, when calculating the sub-alliance's profit, it is only necessary to adjust the range of set $C$ and set $\mathrm{O}$ in Formulas (8)-(12). When the LLP does not provide the distribution service, the nodes with installation demands cannot enjoy the service, which will incur a penalty cost. The penalty cost is calculated by formula (14).

Table 1. Alliance combination mode.

\begin{tabular}{ccccccc}
\hline & 1 & $\mathbf{2}$ & $\mathbf{3}$ & $\mathbf{4}$ & $\mathbf{5}$ & $\mathbf{6}$ \\
\hline $\mathrm{O}$ & $\{1\}$ & $\{2\}$ & $\{3\}$ & $\{1,2\}$ & $\{1,3\}$ & $\{2,3\}$ \\
$\mathrm{C}$ & $D^{L} \cup D^{V}$ & $D^{P} \cup D^{V}$ & $D^{E} \cup D^{V}$ & $D^{L} \cup D^{P} \cup D^{V}$ & $D^{L} \cup D^{E} \cup D^{V}$ & $D^{P} \cup D^{E} \cup D^{V}$ \\
\hline
\end{tabular}

\section{Results}

The allocation of profits based on multimodal transport is obviously a nondeterministic polynomial-time hard problem. Macioszek makes a detailed comparison of existing open-source software solutions for freight transport planning [48]. These opensource software solutions can help solve the large-scale route optimization problem of multimodal transport for last mile delivery. Before route optimization, this paper first allocates the distribution orders among three transport modes according to the specified strategy, which reduces the complexity of the route optimization problem to a certain extent.

GA was first proposed by John Holland [49]. The algorithm is designed according to bio-evolutionary laws in nature, and it is a method of searching for optimal solutions by simulating the process of natural selection. The algorithm is mainly composed of three operators: selection, crossover, and mutation. When solving complex combinatorial optimization problems, it can usually achieve good optimization results quickly. The focus of this research is to propose a design of multimodal transport for last mile delivery in rural areas, and the solution method of the model is not the focus. Therefore, in order to get a better solution quickly to meet the requirements of the application, GA is taken to solve the route optimization problem in this research. 


\subsection{Parameter Setting}

In this research, we randomly generate 30 points in the range of $50 \times 50\left(\mathrm{~km}^{2}\right)$ as distribution nodes. In order to make the distribution nodes evenly distributed in this range as much as possible, the Euclidean distance between any two points is limited to more than $7(\mathrm{~km})$. In order to facilitate recording, we round the coordinates of randomly generated nodes. Meanwhile, the LLP is in the center of the range, and the coordinate is $(25,25)$. The coordinates of the nodes are shown in Table 2.

Table 2. Distribution node coordinates.

\begin{tabular}{ccccccccccc}
\hline 1 & 2 & 3 & 4 & 5 & 6 & 7 & 8 & 9 & 10 \\
\hline$(9,35)$ & $(35,4)$ & $(18,44)$ & $(35,20)$ & $(39,48)$ & $(46,45)$ & $(20,11)$ & $(33,12)$ & $(9,50)$ & $(41,33)$ \\
\hline 11 & 12 & 13 & 14 & 15 & 16 & 17 & 18 & 19 & 20 \\
\hline$(1,1)$ & $(27,44)$ & $(18,33)$ & $(31,29)$ & $(47,17)$ & $(14,15)$ & $(12,27)$ & $(5,15)$ & $(1,37)$ & $(45,6)$ \\
\hline 21 & 22 & 23 & 24 & 25 & 26 & 27 & 28 & 29 & 30 \\
\hline$(49,28)$ & $(40,15)$ & $(6,43)$ & $(11,4)$ & $(33,36)$ & $(1,9)$ & $(28,18)$ & $(3,27)$ & $(20,2)$ & $(26,37)$ \\
\hline
\end{tabular}

We assume that the number of orders at each node follows a uniform distribution within a certain range, and the specific variation range is shown in the last column in Table 3. We assume that there are five PT vehicles in total, that each vehicle passes through six nodes, and that the transportation route of each vehicle is fixed and unchangeable. The number of nodes with installation service demands is shown in column 2 of Table 3 . These nodes are also the nodes where LLP provides distribution services. The labor costs of different transport modes are as follows: $e_{1}=100, e_{2}=0, e_{3}=20, e_{i 1}^{v}=20$. $e_{i 1}^{v}$ refers to the fixed labor cost when the villagers pick up orders by themselves. The penalty cost $b_{i}=60$.

\subsection{Cost-Benefit Analysis}

The distribution cost of each transport mode is shown in Table 3.

Table 3. Distribution cost of each transport mode.

\begin{tabular}{|c|c|c|c|c|c|c|c|c|c|c|c|}
\hline & \multirow{2}{*}{$D^{l}$} & \multirow{2}{*}{$T C_{c}$} & \multirow{2}{*}{$T C_{M}$} & \multirow{2}{*}{ Profits } & \multicolumn{6}{|c|}{ Subsets } & \multirow{2}{*}{ Orders } \\
\hline & & & & & $\{1\}$ & $\{2\}$ & $\{3\}$ & $\{1,2\}$ & $\{1,3\}$ & $\{2,3\}$ & \\
\hline 1 & 5 & 1321.8 & 303.2 & 1018.6 & 718.1 & 540.3 & 723.6 & 378.4 & 577.7 & 427.8 & $(1,20)$ \\
\hline 2 & 5 & 1310.5 & 421.8 & 888.7 & 737.0 & 998.7 & 856.8 & 683.8 & 651.3 & 613.8 & $(10,20)$ \\
\hline 3 & 5 & 1438.0 & 813.9 & 624.1 & 1105.6 & 1138.7 & 1121.8 & 1004.1 & 1038.9 & 866.0 & $(20,30)$ \\
\hline 4 & 3 & 1392.1 & 608.2 & 783.9 & 981.4 & 1030.4 & 951.8 & 918.4 & 823.3 & 678.0 & $(10,30)$ \\
\hline 5 & 4 & 1364.7 & 659.8 & 704.9 & 1100.3 & 1151.0 & 971.6 & 987.1 & 852.5 & 865.8 & $(10,30)$ \\
\hline 6 & 5 & 1303.2 & 542.2 & 761.0 & 1104.1 & 1149.4 & 980.0 & 822.8 & 759.3 & 763.1 & $(10,30)$ \\
\hline 7 & 6 & 1417.7 & 700.7 & 717.0 & 1114.4 & 1147.3 & 1118.0 & 905.6 & 920.4 & 814.6 & $(10,30)$ \\
\hline
\end{tabular}

As can be seen from Table 3, with the increase of orders at each distribution node, the distribution cost of different transport modes exhibits growth trends (data in rows 1 to 3 of Table 3). The reason is that, with the increase of orders at each node, if the total capacity of distribution vehicles remains unchanged, the distribution times will increase, thus increasing the total distribution cost. It can be seen from Table 3 that the distribution cost of the two collaborative transport modes may be higher than that of a single transport mode. For example, in the fifth row of Table 3, the distribution cost of collaborative distribution by LLP and PT is 987.1 yuan, but the distribution cost of CL only is 971.6 yuan. This is because the composition of distribution cost is not only related to transportation distance but also to fixed labor cost, penalty cost caused by not meeting the installation requirements, and other factors. Therefore, multimodal transport for last mile delivery is not always better 
than single-mode transport, and a comprehensive analysis should be carried out when selecting distribution modes. In addition, as shown in Table 3 (rows 4 to 7), when the order quantity of each node is relatively stable and changes little, and there are few nodes with installation demands, a change in the number of installation nodes has little impact on the distribution cost.

For last mile delivery in rural areas, the LLP provides distribution services and occupies a dominant position. It is unrealistic to use PT or CL modes alone without the participation of the LLP. In addition, if the LLP does not provide order information, the PT and CL modes cannot themselves generate profits. When calculating the distribution costs in different transport modes, all orders are handed over to the corresponding mode by default and the order splitting problem is not considered. Thus, when calculating profits, there must be $v\left(s_{1} \cup s_{2}\right)<v\left(s_{1}\right)+v\left(s_{2}\right)$. In this paper, Shapley value is used for profit allocation in order to analyze the marginal contribution rate of different transport modes. According to the data of Table 3 and Formula (16), the profit of each transport mode and Shapley values are calculated, and the results are shown in Table 4.

Table 4. Shapley value and profit of each mode.

\begin{tabular}{cccccccccc}
\hline \multirow{2}{*}{$\boldsymbol{D}^{\boldsymbol{l}}$} & \multirow{2}{*}{ Orders } & \multicolumn{7}{c}{ Profits } & \multirow{2}{*}{ Shapley Value } \\
\cline { 3 - 8 } & & $\{\mathbf{1}\}$ & $\{\mathbf{2}\}$ & $\{\mathbf{3}\}$ & $\{\mathbf{1 , 2}\}$ & $\{\mathbf{1 , 3}\}$ & $\{\mathbf{2 , 3}\}$ & $\{\mathbf{1 , 2 , 3}\}$ & \\
\hline 5 & $(1,20)$ & 603.7 & 781.5 & 598.2 & 943.4 & 744.1 & 894 & 1018.6 & $\{294.1,457.9,266.6\}$ \\
5 & $(10,20)$ & 573.5 & 311.8 & 453.7 & 626.7 & 659.2 & 696.7 & 888.7 & $\{341.9,229.8,317.0\}$ \\
5 & $(20,30)$ & 332.4 & 299.3 & 316.2 & 433.9 & 399.1 & 572.0 & 624.1 & $\{164.4,234.3,225.4\}$ \\
3 & $(10,30)$ & 410.7 & 361.7 & 440.3 & 473.7 & 568.8 & 714.1 & 783.9 & $\{200.2,248.4,335.2\}$ \\
4 & $(10,30)$ & 264.4 & 213.7 & 393.1 & 377.6 & 512.2 & 498.9 & 705.0 & $\{204.0,172.0,329.0\}$ \\
5 & $(10,30)$ & 199.1 & 153.8 & 323.2 & 480.4 & 543.9 & 540.1 & 761.0 & $\{231.2,206.7,323.1\}$ \\
6 & $(10,30)$ & 303.3 & 270.4 & 299.7 & 512.1 & 497.3 & 603.1 & 717.0 & $\{212.3,248.7,256.0\}$ \\
\hline
\end{tabular}

As can be seen from Table 4, when the order quantity of each node is small and the vehicle capacity is large (data in row 1 of Table 4), the marginal contribution rate of the PT mode will be much higher than that of the other two transport modes. This is because the departure frequency and transportation route of the PT mode have been fixed and this mode only provides a distribution service. Compared with other transport modes, when the order quantity of each node is small, the number of nodes that can be delivered by PT vehicle will be greater, while the remaining nodes delivered by other transport modes will be fewer, and the distribution cost of the rural logistics system will be greatly reduced. It can be seen from rows 4 to 7 in Table 4 that when the order demand of each node tends to be stable, the marginal contribution rate of the CL mode is often greater than that of the other two transport modes. Compared with the other two transport modes, the transportation route of CL is flexible [28] (compared with PT) and the unit distribution cost is low (compared with LLP). After the overall planning of the transportation route, the advantages of the CL mode will be more obvious, and the marginal contribution rate is often higher than the other two transport modes. Thus, under different application scenarios (different parameter settings), the marginal contribution rate of each transport mode is often different. When using multimodal transport to solve the last mile delivery problem in rural areas, the profit allocation should be carried out reasonably according to the marginal contribution rate of each transport mode.

\subsection{Route Analysis}

In this section, we take the parameters (second row in Table 3) as an example to represent order allocation and route optimization. The specific calculation results are shown in Table 5. Among them, the nodes passed by each vehicle represent order allocations. In addition, the number in Table 5 represents the node number and the corresponding coordinates are shown in Table 2. The number in brackets is the node number to be delivered by PT. 
Table 5. Order allocation and route optimization.

\begin{tabular}{cc}
\hline Transport Mode & Distribution Route \\
\hline LLP & $24-18-17-3-13$ \\
\hline & $13-3-9-23-19-1:(9-23-19)$ \\
PT & $17-28-18-26-11-24:(28-26-11)$ \\
& $30-12-5-6-10-25:(5-6)$ \\
& $27-15-20-22-4:(21-20)$ \\
CL & $30-12-1 ; 16-7-27 ; 14-10-25 ; 4-15-22$ \\
\hline
\end{tabular}

\section{Discussion}

Last mile delivery has become a key issue restricting the sustainable development of rural logistics. At present, most of the research focuses on the optimization of a specific distribution mode, while there is less research on using multimodal transport to solve the problem of last mile delivery, especially last mile delivery in rural areas [5-33]. Distribution mode selection, order allocation strategy, route optimization, and profit allocation are the core problems for last mile delivery in rural areas. This work presents a comprehensive exploration of multimodal transport for last mile delivery in rural areas.

By analyzing the cost-benefit structure of multimodal transport, as shown in Table 3, it is discovered that the number of orders will directly affect the profits of multimodal transport for last mile delivery, and multimodal transport can effectively solve the problem of fewer orders at each distribution node. The reason is that, based on the exact distribution mode, the number of orders directly affects the number of distribution vehicles and thereby affects the distribution cost. When the order quantity of each node is small, the PT mode can complete the distribution tasks of most nodes, while the distribution cost of the PT mode is very low, which can greatly reduce the cost of multimodal transport for last mile delivery. In addition, the remaining nodes without value-added services will adopt the CL mode for last mile delivery. Compared with the LLP mode, the CL mode is more flexible and the distribution cost is lower. Therefore, when the order quantity of each node is small, multimodal transport is more suitable for last mile delivery in rural areas. It can be seen that unreasonable transport mode combinations will increase the distribution cost of the logistics system. This is because the composition of distribution cost is not only related to transportation distance but also to fixed labor cost, the penalty cost resulting from not meeting the requirements, and other factors. When carrying out multimodal transport construction for last mile delivery in rural areas, it is necessary for the government or enterprises concerned to select a reasonable mode combination according to the specific situation.

The results of the profit allocation (Table 4) indicate that the number of orders at each node and the capacity of distribution vehicles will affect the marginal contribution rate of the corresponding transport mode. When the order quantity of each distribution node is small, the marginal contribution rate of the PT mode is often high, which can make a greater contribution to the profit of multimodal transport for last mile delivery. In this situation, the multimodal transport system should make full use of the advantage of the PT mode and increase profit as much as possible. With the increase of order quantity, the marginal contribution rate of the PT mode gradually decreases due to the limitation of vehicle capacity, while the marginal contribution rate of the CL mode gradually increases due to its flexibility and low distribution cost. In this case, the CL mode should be paid more attention and given more profits to promote its sustainable development so as to improve the profits of the multimodal transport system for last mile delivery. Therefore, the relevant governments or enterprises should allocate profits according to the specific situation combined with the marginal contribution rate of each transport mode and adjust the profit allocation strategy when the situation changes so as to promote the sustainable development of rural logistics. 


\section{Conclusions}

The backwardness of the logistics distribution system has gradually become one of the key problems restricting the sustainable development of the rural economy, and multimodal transport is regarded as one of the main methods for solving this issue. However, multimodal transport for last mile delivery in rural areas has not been widely accepted by the general public due to poor coordination among transport modes and difficulties in terms of cost-benefit analyses. To address these problems, this research first proposed a design of multimodal transport for last mile delivery in rural areas. Then, a cost-benefit model for multimodal transport was proposed, which uses GA to solve the model. Finally, the Shapley value was used to fairly allocate the profits and represent the marginal contribution of each mode in the multimodal transport system. The numerical results showed that multimodal transport can effectively reduce the distribution cost of last mile delivery in rural areas. When the order demand of each node tends to be stable, the marginal contribution of the CL mode is often greater than that of the other two distribution modes. The marginal contribution of the PT mode is highest only when the number of orders per node is very small.

The contributions of this research are threefold. Firstly, this work innovatively proposes a design for multimodal transport for last mile delivery in rural areas which can provide an important reference for governments or enterprises to adopt multimodal transport systems to solve the problem of last mile delivery in rural areas. Secondly, this research solves the issue of order allocation and transport route planning in the context of multimodal transport. This provides the possibility for the further implementation of multimodal transport systems for last mile delivery. Finally, this paper analyzes the costs and benefits under different modes and allocates profits according to the Shapley value. The results can be directly used for multimodal transport in rural logistics.

There are also some limitations, however. On one hand, the logistic service's quality is critical for the sustainability of rural e-commerce and logistic delivery systems [50,51]. Many scholars have carried out a lot of research on logistic service quality and have made many outstanding achievements [52-56]. The main purpose of this research being to solve the daily distribution problem for last mile delivery in rural areas, cost is the core indicator considered in this paper. In the future, we will consider other indicators of logistic service quality to make the model more comprehensive. On the other hand, when allocating profits, this work does not consider whether an enterprise or a transport mode occupies a dominant position in the multimodal transport system. In reality, there is often an enterprise that occupies a dominant position in such a system. In the future, this factor should be taken into account when dealing with profit allocation.

Author Contributions: Conceptualization, X.K. and Y.Z.; methodology, X.K.; software, D.L.; validation, L.Q. and X.L.; investigation, X.K.; resources, D.L.; data curation, L.Q.; writing-original draft preparation, X.K. and Y.Z.; writing-review and editing, X.K.; visualization, X.L.; supervision, L.Q.; project administration, X.K.; funding acquisition, X.K. All authors have read and agreed to the published version of the manuscript.

Funding: This research was funded by the Science and Technology Research Project of Henan Province (No. 212102310059).

Institutional Review Board Statement: Not applicable.

Informed Consent Statement: Not applicable.

Data Availability Statement: Not applicable.

Conflicts of Interest: The authors declare no conflict of interest. 


\section{References}

1. Available online: http://english.mofcom.gov.cn/article/newsrelease/press/202111/20211103214792.shtml (accessed on 18 January 2022).

2. Archetti, C.; Bertazzi, L. Recent challenges in Routing and Inventory Routing: E-commerce and last-mile delivery. Networks 2021, 77, 255-268. [CrossRef]

3. Macioszek, E. First and last mile delivery-problems and issues. In Proceedings of the Scientific and Technical Conference Transport Systems Theory and Practice, Katowice, Poland, 18-20 September 2017; pp. 147-154.

4. Dantzig, G.B.; Ramser, J.H. The truck dispatching problem. Manag. Sci. 1959, 6, 80-91. [CrossRef]

5. Solomom, M.M. Algorithms for the Vehicle Routing and Scheduling Problems with Time Windows Constrains. Oper. Res. 1987, 35, 254-265. [CrossRef]

6. Desrochers, M.; Desrosiers, J.; Solomom, M. A New Optimization Algorithm for the Vehicle Routing Problem with Time Windows. Oper. Res. 1992, 40, 342-354. [CrossRef]

7. Niu, Y.Y.; Yang, Z.H.; Chen, P.; Xiao, J.H. Optimizing the green open vehicle routing problem with time windows by minimizing comprehensive routing cost. J. Clean. Prod. 2018, 171, 962-971. [CrossRef]

8. Pan, B.B.; Zhang, Z.Z.; Lim, A. Multi-trip time-dependent vehicle routing problem with time windows. Eur. J. Oper. Res. 2021, 291, 218-231. [CrossRef]

9. Laporte, G.; Nobert, Y.; Arpin, D. An exact algorithm for solving a capacitated location-routing problem. Ann. Oper. Res. 1986, 6, 293-310. [CrossRef]

10. Laporte, G.; Nobert, Y.; Taillefer, S. Solving a family of multi-depot vehicle routing and location-routing problems. Transp. Sci. 1988, 22, 161-172. [CrossRef]

11. Aras, N.; Aksen, D.; Tekin, M.T. Selective multi-depot vehicle routing problem with pricing. Transp. Res. Part C Emer. Tehnol. 2011, 19, 866-884. [CrossRef]

12. Wang, Y.; Li, Q.; Guan, X.Y.; Fan, J.X.; Xu, M.Z.; Wang, H.Z. Collaborative multi-depot pickup and delivery vehicle routing problem with split loads and time windows. Knowl.-Based Syst. 2021, 231, 107412. [CrossRef]

13. Erdogan, S.; Hooks, E.M. A green vehicle routing problem. Transp. Res. Part E Logist. Transp. Rev. 2012, 48, 100-114. [CrossRef]

14. Asghari, M.; Mirzapour, S.M.J. Green vehicle routing problem: A state-of-the-art review. Int. J. Prod. Econ. 2021, $231,107899$. [CrossRef]

15. Doerner, K.F.; Schmid, V. Survey: Matheuristics for Rich Vehicle Routing Problems. Int. Workshop Hybrid Metaheuristics 2010, 6373, 206-221.

16. Caceres-Cruz, J.; Arias, P.; Guimarans, D.; Riera, D.; Juan, A.A. Rich vehicle routing problem: Survey. ACM Comput. Surv. 2014, 47, 1-28. [CrossRef]

17. Lahyani, R.; Khemakhem, M.; Semet, F. Rich vehicle routing problems: From a taxonomy to a definition. Eur. J. Oper. Res. 2015, 241, 1-14. [CrossRef]

18. Baker, B.M.; Ayechew, M.A. A genetic algorithm for the vehicle routing problem. Comput. Oper. Res. 2003, 30, 787-800. [CrossRef]

19. Rabbouch, B.; Saâdaoui, F.; Mraihi, R. Efficient implementation of the genetic algorithm to solve rich vehicle routing problems. Oper. Res. 2021, 21, 1763-1791. [CrossRef]

20. Kuo, Y. Using simulated annealing to minimize fuel consumption for the time-dependent vehicle routing problem. Comput. Ind. Eng. 2010, 59, 157-165. [CrossRef]

21. Vincent, F.Y.; Jewpanya, P.; Redi, A.A.N.P.; Tsao, Y.C. Adaptive neighborhood simulated annealing for the heterogeneous fleet vehicle routing problem with multiple cross-docks. Comput. Oper. Res. 2021, 129, 105205.

22. Archetti, C.; Speranza, M.G.; Hertz, A.A. A tabu search algorithm for the split delivery vehicle routing problem. Transp. Sci. 2006, 40, 64-73. [CrossRef]

23. Gmira, M.; Gendreau, M.; Lodi, A.; Potvin, J.Y. Tabu search for the time-dependent vehicle routing problem with time windows on a road network. Eur. J. Oper. Res. 2021, 288, 129-140. [CrossRef]

24. Bell, J.E.; McMullen, P.R. Ant colony optimization techniques for the vehicle routing problem. Adv. Eng. Inform. 2004, 18, 41-48. [CrossRef]

25. Yu, B.; Yang, Z.Z.; Yao, B. An improved ant colony optimization for vehicle routing problem. Eur. J. Oper. Res. 2009, 196, 171-176. [CrossRef]

26. Jia, Y.H.; Mei, Y.; Zhang, M. A Bilevel Ant Colony Optimization Algorithm for Capacitated Electric Vehicle Routing Problem IEEE Trans. Cybern. 2021, 1-14. [CrossRef]

27. Rougès, J.F.; Montreuil, B. Crowdsourcing delivery: New interconnected business models to reinvent delivery. In Proceedings of the 1st International Physical Internet Conference, Quebec City, QC, Canada, 28-30 May 2014.

28. Carbone, V.; Rouquet, A.; Roussat, C. The rise of crowd logistics: A new way to co-create logistics value. J. Bus. Logist. 2017, 38, 238-252. [CrossRef]

29. Wang, Y.; Zhang, D.; Liu, Q.; Shen, F.; Lee, L.H. Towards enhancing the last-mile delivery: An effective crowd-tasking model with scalable solutions. Transp. Res. Part E Logist. Transp. Rev. 2016, 93, 279-293. [CrossRef]

30. Huang, K.; Ardiansyah, M.N. A decision model for last-mile delivery planning with crowdsourcing integration. Comput. Ind. Eng. 2019, 135, 898-912. [CrossRef] 
31. Kafle, N.; Zou, B.; Lin, J. Design and modeling of a crowdsource-enabled system for urban parcel relay and delivery. Transp. Res. Part B Methodol. 2017, 99, 62-82. [CrossRef]

32. Akeb, H.; Moncef, B.; Durand, B. Building a collaborative solution in dense urban city settings to enhance parcel delivery: An effective crowd model in Paris. Transp. Res. Part E Logist. Transp. Rev. 2018, 119, 223-233. [CrossRef]

33. Chen, C.; Pan, S. Using the Crowd of Taxis to Last Mile Delivery in E-Commerce: A methodological research. In Service Orientation in Holonic and Multi-Agent Manufacturing, 1st ed.; Borangiu, T., Trentesaux, D., Thomas, A., Mcfarlane, D., Eds.; Springer: Cambridge, UK, 2016; Volume 640, pp. 61-70.

34. Zhou, C.; Li, H.; Wang, W.; Lee, L.H.; Chew, E.P. Connecting the Belt and Road through sea-rail collaboration. Front. Eng. Manag. 2017, 4, 315-324. [CrossRef]

35. Dastjerdi, A.M.; Kaplan, S.; de Abreu e Silva, J.; Nielsen, O.A.; Pereira, F.C. Participating in environmental loyalty program with a real-time multimodal travel app: User needs, environmental and privacy motivators. Transp. Res. Part D Transp. Environ. 2019, 67, 223-243. [CrossRef]

36. Wang, Q.Z.; Chen, J.M.; Tseng, M.L.; Luan, H.M.; Ali, M.H. Modelling green multimodal transport route performance with witness simulation software. J. Clean. Prod. 2020, 248, 119245. [CrossRef]

37. Jiang, J.; Zhang, D.; Meng, Q.; Liu, Y.J. Regional multimodal logistics network design considering demand uncertainty and $\mathrm{CO}_{2}$ emission reduction target: A system-optimization approach. J. Clean. Prod. 2020, 248, 119304. [CrossRef]

38. Xu, G.Y.; Zhang, R.; Xu, S.X.; Kou, X.F.; Qiu, X. Personalized Multimodal Travel Service Design for sustainable intercity transport. J. Clean. Prod. 2021, 308, 127367. [CrossRef]

39. Ayed, H.; Galvez-Fernandez, C.; Habbas, Z.; Khadraoui, D. Solving time-dependent multimodal transport problems using a transfer graph model. Comput. Ind. Eng. 2011, 61, 391-401. [CrossRef]

40. Qiu, X.; Xu, S.X.; Xu, G. Pricing and scheduling of barge hinterland transportation service for inbound containers. Transp. Res. Part E Logist. Transp. Rev. 2021, 156, 102515. [CrossRef]

41. Chen, W.D.; Huang, W.; Zhang, R.J.; He, P.; Li, H.; Wang, Q. Research on the Development Strategy of Rural Logistics in China Post. IOP Conf. Ser. Earth. Environ. Sci. 2019, 330, 052029.

42. Gong, X. Coupling coordinated development model of urban-rural logistics and empirical study. Math. Probl. Eng. 2019, 2019, 9026795. [CrossRef]

43. Yang, F.; Dai, Y.; Ma, Z.J. A cooperative rich vehicle routing problem in the last-mile logistics industry in rural areas. Transp. Res. Part E Logist. Transp. Rev. 2020, 141, 102024. [CrossRef]

44. Park, J.; Kim, S.; Suh, K. A comparative analysis of the environmental benefits of drone-based delivery services in urban and rural areas. Sustainability 2018, 10, 888. [CrossRef]

45. Kim, S.J.; Lim, G.J.; Cho, J.; Cote, M.J. Drone-aided healthcare services for patients with chronic diseases in rural areas. J. Intell. Robot. Syst. 2017, 88, 163-180. [CrossRef]

46. Koiwanit, J. Analysis of environmental impacts of drone delivery on an online shopping system. Adv. Clim. Chang. Res. 2018, 9, 201-207. [CrossRef]

47. Shapley, L.S. Stochastic games. Proc. Natl. Acad. Sci. USA 1953, 39, 1095-1100. [CrossRef] [PubMed]

48. Macioszek, E. Freight transport planners as information elements in the last mile logistics. In Proceedings of the Scientific and Technical Conference Transport Systems Theory and Practice, Katowice, Poland, 17-19 September 2018; pp. $242-251$.

49. Holland, J.H. Genetic algorithms and the optimal allocation of trials. SIAM J. Comput. 1973, 2, 88-105. [CrossRef]

50. Ageron, B.; Gunasekaran, A.; Spalanzani, A. Sustainable supply management: An empirical study. Int. J. Prod. Econ. 2012, 140, 168-182. [CrossRef]

51. Zhu, Q.; Sarkis, J.; Geng, Y. Green supply chain management in China: Pressures, practices and performance. Int. J. Oper. Prod. Manag. 2005, 25, 449-468. [CrossRef]

52. Kilibarda, M.; Andrejić, M.; Popović, V. Research in logistics service quality: A systematic literature review. Transport 2020, 35, 224-235.

53. Jiang, X.H.; Wang, H.Y.; Guo, X.C.; Gong, X.L. Using the FAHP, ISM, and MICMAC approaches to study the sustainability influencing factors of the last mile delivery of rural e-commerce logistics. Sustainability 2019, 11, 3937. [CrossRef]

54. Juga, J.; Juntunen, J.; Grant, D.B. Service quality and its relation to satisfaction and loyalty in logistics outsourcing relationships. Manag. Serv. Qual. 2010, 20, 496-510. [CrossRef]

55. Gotzamani, K.; Longinidis, P.; Vouzas, F. The logistics services outsourcing dilemma: Quality management and financial performance perspectives. Supply Chain Manag. 2010, 15, 438-453. [CrossRef]

56. Yu, M. Model for evaluating the e-commerce logistics service quality with hesitant fuzzy uncertain linguistic information. J. Intell. Fuzzy Syst. 2017, 32, 4023-4029. [CrossRef] 